\title{
Synthesis and Characterization of Metal-Complexes Rigid Rod Formation in Water from Dicarboxylic Bolaamphiphile
}

\author{
Giriraj S. Mandloi ${ }^{1}$, P. M. Selvakumar ${ }^{2}$, Smita Joshi $^{3}$, Sulbha Amlathe ${ }^{1^{*}}$ \\ ${ }^{1}$ Research Scholar, BUIT, BU, Bhopal, M.P. (INDIA)

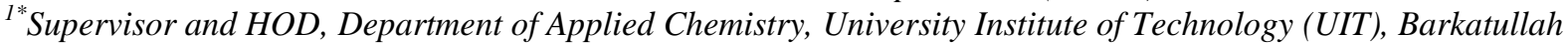 \\ University, Bhopal-462 064, M. P., (INDIA) \\ ${ }^{2}$ Department of Chemistry, Karunya University, Coimbatore 641114, Taminadu, (INDIA) \\ ${ }^{3}$ Head of Chemistry Department, Sarojini Naidu Govt. Girls College, Bhopal-462 064, M. P., (INDIA)
}

\begin{abstract}
The synthesis, characterization of, 2,2'-[ethane-1,2-diylbis(oxycarbonyl)]dibenzoic acid, and rigid rod formation of diester-based bolaamphiphiles in water was analyzed by FE-SEM/EDS, UV-Visible and using simultaneous TGA, DSC and DTA measurement under non-isothermal condition in $\mathrm{N}_{2}$ atmosphere. The bolaamphiphiles proved to be coordinated to divalent transition-metal cat ions, such as $\mathrm{Co}^{+}, \mathrm{Ni}^{2+}, \mathrm{Cu}^{2+}$, and $\mathrm{Zn}^{2+}$, giving precipitates, and colloidal dispersions upon self-assembly at room temperature. FT-IR and powder $X R D$ measurement supported the existence of a rigid rods completing $\left[M\left(L_{1} H_{2}\right) \mathrm{OH}\right]$ with metal cat ions indicates the formation of self-assembled rigid rod structure mediated through $\mathrm{O}-\mathrm{H} \ldots \mathrm{O} ; \mathrm{C}-\mathrm{H} \ldots \mathrm{O}$ interaction of the end carboxylic acids.
\end{abstract}

Keywords: Self assemble bolaamphiphile, 2, 2'-[ethane-1, 2-diylbis (oxycarbonyl)] dibenzoic acid, rigid rod.

\section{Introduction}

Our current interest in transition chemistry began with the preparation and characterization of metal complexes rigid rod formation in water containing dicarboxylic acid. The reports on metal acetates [1-3] and the preparation of metal complexes rigid rod structures have attracted much attention in materials science field [46]. Carboxylic amphiphiles form a variety of self-assemblies such as micelles, vesicles, fibres, and crystals in water. The formation behaviour strongly depends upon hydration states, salt concentrations, and $\mathrm{pH}$ conditions in aqueous dispersions $[8,9]$. In particular, molecular self-assembling system has provided well-defined one, two, and three-dimensional organic templates for the metal complexation [10-12]. The $\mathrm{pH}$ values and the kind of counter cations have a remarkable effect on their self-assembling properties because of hydrophilic carboxylic functionalities in water [12-13].

The thermal behaviour of solid organic compounds depends mainly on the characteristic intermolecular cohesive forces in the crystal structure [14]. Carboxylic acids can form hydrogen bonds as they exhibit the O-H proton-donating and the $\mathrm{C}=\mathrm{O}$ proton accepting group. Decomposition processes for various carboxylates metal complexes under heating were studied widely during last decades; a detailed review is presented in [15], therefore, this paper describes the coordinating properties of the acids and thermal characterisation of their metal complexes.

\section{Experimental}

All the chemicals were procured from Aldrich \& Co. and are used without any further purification. The preparation and characterization of 2, 2'-[ethane-1, 2-diylbis (oxycarbonyl)] dibenzoic acid has been reported [16-18]. The thermal gravimetric analysis (TGA, DSC and DTA) ware carried out on Mettler Toledo analyzer (Model TGA/DSC1, STAR ${ }^{\mathrm{e}}$ System SW 9.20., USA), at central instrument facility centre CSIR, AMPRI, Bhopal using nitrogen atmosphere $\left(40-50 \mathrm{~cm}^{3} / \mathrm{min}\right)$, with the experimental set up consisted of a heating ramp from 25 to $1200^{\circ} \mathrm{C}$ at $10^{\circ} \mathrm{C} \mathrm{min}{ }^{-1}$. The morphology (FE-SEM/EDS) was performed on a Model JOEL JSM5600, Japan, Powder X-ray diffraction (XRD) patterns of dried samples were taken by the reflection method on a Rigaku diffractometer (RINT 2000) using graded d-space elliptical side by side multilayer optics monochromated $\mathrm{CuK} \alpha$ radiation $(50 \mathrm{kV}, 40 \mathrm{~mA})$ and FT-IR spectra were recorded using $\mathrm{KBr}$ pellets on a Perkin-Elmer Spectrum GX FT-IR spectrometer.

\subsection{Self-assemble of the metal-complexed diester dicarboxylic bolaamphiphiles}

The diester dicarboxylic bolaamphiphile metal-complexes have been synthesized by deprotonation of the terminal carboxylic group by the addition of $1 \mathrm{mmol}$ of sodium hydroxide can allow the bolaamphiphiles to be soluble in water. Aqueous solutions of the sodium salts of the bolaamphiphile 2, 2'-[ethane-1, 2diylbis(oxycarbonyl)]dibenzoic acid $(2 \mathrm{mmol}, 5 \mathrm{~mL})$ were added to aqueous solutions of metal salts $\mathrm{Co}(\mathrm{OAc})_{2}$, $\mathrm{Ni}(\mathrm{OAc})_{2}, \mathrm{Cu}(\mathrm{OAc})_{2}, \mathrm{Zn}(\mathrm{OAc})_{2}(2 \mathrm{mmol}, 5 \mathrm{~mL})$ with stirring at room temperature. The reaction mixtures were 
allowed to stand for 1 day at same temperature and they were subjected to the structural and morphological analyses.

\section{Results and discussion}

\subsection{Self-assembly of the diester dicarboxylic bolaamphiphile with metal cations}

The self-assembling behaviours of the bolaamphiphile with $\mathrm{Co}^{2+}, \mathrm{Ni}^{2+}, \mathrm{Cu}^{2+}$, and $\mathrm{Zn}^{2+}$ at room temperature were summarized. The complexes of 1-4 appeared as precipitates, colloidal dispersions and hydrogel, in aqueous solutions. Fig. 1 shows the appearance of the all metal complexes upon self-assembly at room temperature. A proposed structure of the copper (II) acetates complex and a schematic illustration of the molecular arrangement within the metalcomplexed rigid rod are shown in Fig. 2. We can also observe colored solutions with trace amount of colloidal dispersions and hydrogel with all metals at 50,60 and $70^{\circ} \mathrm{C}$ temperature. The colloidal dispersions of $\mathbf{1} / \mathrm{Co}^{2+}$, and $\mathbf{2} / \mathrm{Ni}^{2}$ can be considered as a loose hydrogel because they occasionally converted into hydrogels at above $50^{\circ} \mathrm{C}$. We found recrystallization of the $3 / \mathrm{Cu}^{2+}$ complex upon self-assembly at room temperature in 1:1 ethanol: water mixture showing the production of rigid road structure of the complex. Metal cations have a remarkable effect on the formation of the precipitation and colloidal dispersions. $4 / \mathrm{Zn}^{2+}$ and $3 / \mathrm{Cu}^{2+}$ are easy to form the colloidal dispersions at $50^{\circ} \mathrm{C}$ in comparison with $\mathrm{Co}^{2+}$ and $\mathrm{Ni}^{2+}$ respectively. The formation of participation was more favoured with increasing the self-assembling temperature and the connecting mediated through $\mathrm{O}-\mathrm{H} \ldots \mathrm{O} ; \mathrm{C}-\mathrm{H} \ldots \mathrm{O}$ interaction of the end carboxylic acids [16-18]. For the $4 / \mathrm{Zn}^{2+}$ complexe, we observed remarkable temperature effect on the appearance. When the bolaamphiphile was complexes with $3 / \mathrm{Cu}^{2+}$ at 50,60 , and $70^{\circ} \mathrm{C}$, the obtained complexes gave precipitates at temperatures below $50^{\circ} \mathrm{C}$, whereas a colloidal dispersion above $60{ }^{\circ} \mathrm{C}$.

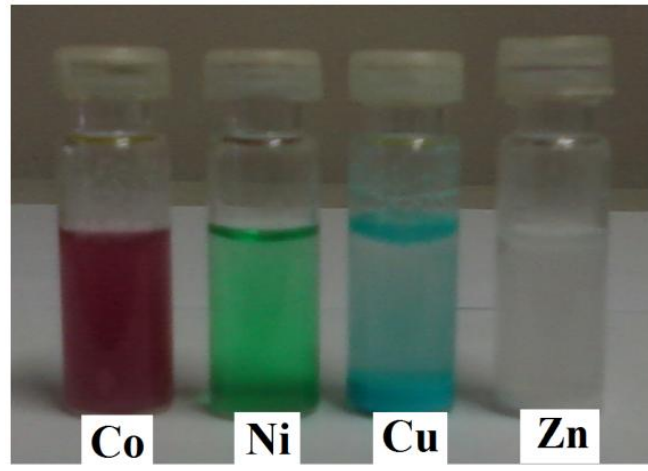

Fig. 1. The appearance of the metal complexes upon self-assembly at room temperature.<smiles>O=C(O)c1ccccc1C(=O)OCCOC(=O)c1ccccc1C(=O)O</smiles>
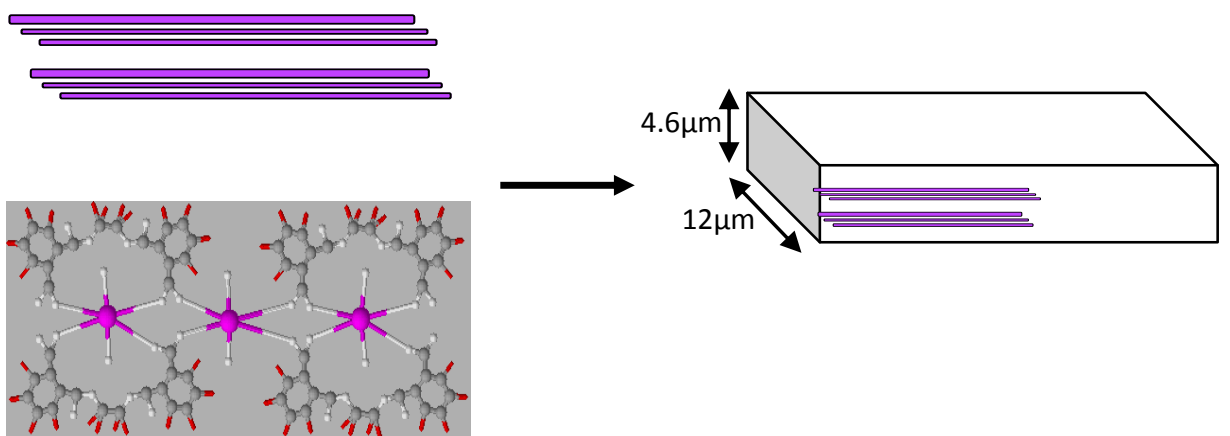

Fig.2. A proposed structure of the copper (II) acetates complex and a schematic illustration of the molecular packing within the rigid rod.

\subsection{Electron microscopic observation}

Field-emission scanning electron microscopy (FE-SEM) of the diester dicarboxylic bolaamphiphile metal complexes was recorded to understand the formation of rigid rod. To clarify the rigid rod structures responsible for the precipitation and the colloidal dispersions, we carried out FE-SEM. Fig. 3 displays microscopic images of the $3 / \mathrm{Cu}^{2+}$ complexes upon self-assembly at room temperature. EF-SEM images revealed 
the existence of rigid rod with widths of $12-15 \mu \mathrm{m}$ and lengths of several hundred micrometers. The widths of the $3 / \mathrm{Cu}^{2+}$ complexed rod are almost similar to those of the organic nanofibers as previously reported [19-20]. The colloidal dispersions of the metal cation complexes are also composed of the rigid rod. We also carried out energy dispersive EDX for the metal complexes. EDX of each rigid rod shows the peaks ascribable to cobalt, nickel, copper, and zinc, respectively Fig. 4.
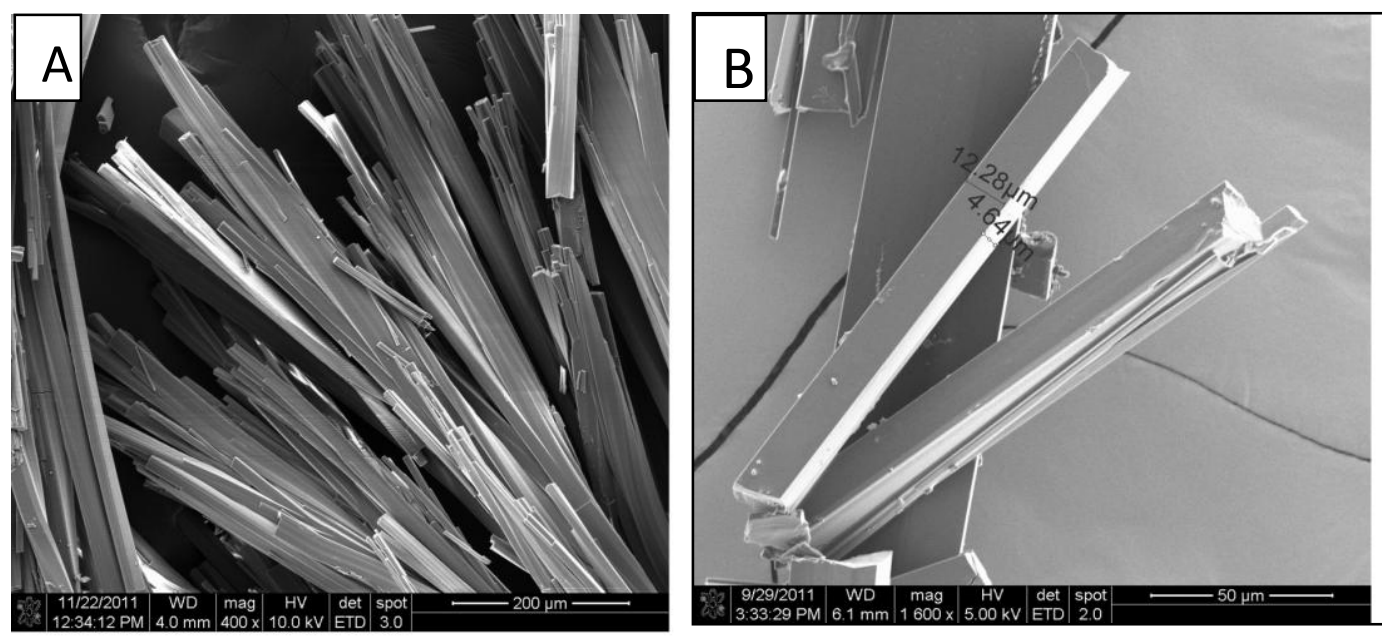

Fig. 3. FE-SEM images of (A) and (B) the $\mathrm{Cu}^{2+}$ complex, self-assembled at room temperature

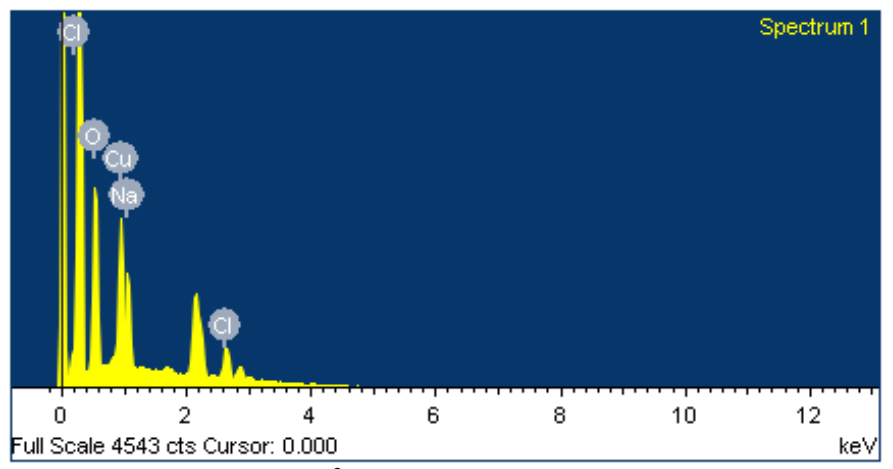

Fig. 4. EDS Spectrum of the $\mathrm{Cu}^{2+}$ complex, self-assembled at room temperature

This finding supported that the rigid rods are actually composed of the metal complexes of bolaamphiphiles. Uniform widths of the metal-complexed rigid rod indicate that both the length of the end terminal carboxylic acids and the kinds of metal cations have little effect on the morphologies of the rigid rod.

\subsection{FT-IR and XRD analysis}

All bolaamphiohilc metal compounds 1-4 possessing carboxyl unit as well as ester functional group in common Fig. 5. The peak at $1700-1730 \mathrm{~cm}^{-1}$ region for all compounds described to the $\mathrm{C}=\mathrm{O}$ stretching mode of end $\mathrm{COOH}$ group characteristic of the formation of carboxylic dimmers [21]. The peak appeared around 3400 $\mathrm{cm}^{-1}$ indicates the presence of carboxylic $\mathrm{OH}$ group. The additional signal in the IR region at $1700-1740 \mathrm{~cm}^{-1}$ region indicates the spacer $\mathrm{COO}$ group. Thus, the two set of IR peak appeared at this region 


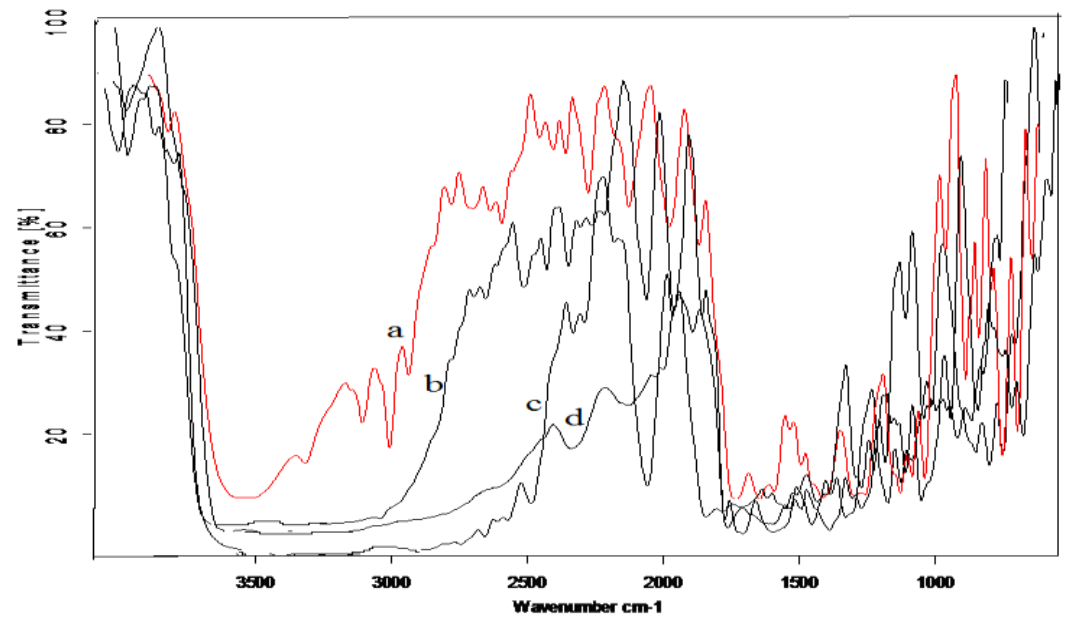

Fig. 5. FT-IR spectra (a) $\mathrm{Co}^{2+},(\mathrm{b}) \mathrm{Ni}^{2+},(\mathrm{c}) \mathrm{Cu}^{2+}$, and (d) $\mathrm{Zn}^{2+}$ complexes upon self-assembly at room temperature

indicates the presence of terminal and spacer $\mathrm{COO}$ group in all these compounds. XRD patterns of the isolated and dried $\mathrm{Co}^{2+}, \mathrm{Ni}^{2+}, \mathrm{Cu}^{2+}$, and $\mathrm{Zn}^{2+}$ complexes upon self-assembly at room temperature are shown in Fig. 6 . Although the intensities are relatively sharp because of crystalline nature of the $3 / \mathrm{Cu}^{2+}$ complexed rigid rod, relatively strong reflection peaks appear in a similar way as the organic rigid rod.

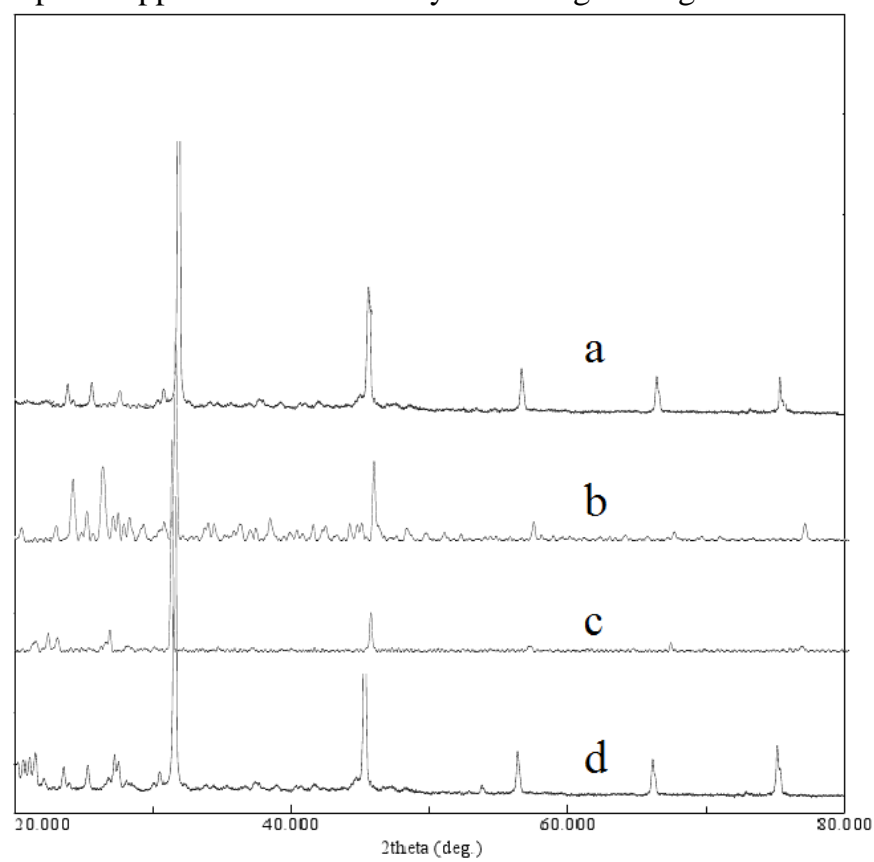

Fig. 6. XRD patterns of the isolated and dried (a) $\mathrm{Co}^{2+},(\mathrm{b}) \mathrm{Ni}^{2+},(\mathrm{c}) \mathrm{Cu}^{2+}$, and (d) $\mathrm{Zn}^{2+}$ complexes upon selfassembly at room temperature

The terminal and spacer $\mathrm{COO}$ group in the bolaamphiphile will favourably form $\beta$-sheet type hydrogen bond networks [23].The absence of strong and periodic reflection peaks in the small-angle region suggests that the rod are based on no long-range lamellar organization. All the results from electron microscopic observation, FT-IR spectrum, and XRD analysis supported that the metal coordination to terminal carboxylate anions takes place on the organic rigid rod.

\subsection{Thermal analysis}

The the thermo gravimetric analysis for metal complexes 1-4 are shown in Fig. 7. Because all the compounds shown similar thermal behaviour, we give below, as an example, a more detailed discussion of the complexes 1-4 series. The TGA curve are shown as \% mass loss versus Temperature, the DSC curve as enthalpy changes and the DTA curve as the rate of mass loss of the temperature. The results are proved the first stage of decomposition of compound 1- 4 under investigation in Nitrogen was dehydration. 


\section{$\mathrm{Co}\left(\mathrm{L}_{1} \mathrm{H}_{2}\right) \mathrm{OH}$ Complex}

The TGA, DTG and DTA profiles of $\mathrm{Co}^{2+}-\mathbf{L}_{\mathbf{1}} \mathbf{H}_{2}$ complex are given in Fig. 7a. The first mass loss about $10.622 \%$ occurs in temperature ranges $25-110^{\circ} \mathrm{C}$ due to dehydration of water molecules. The next exothermic decomposition of the complex occurs in $235-264{ }^{\circ} \mathrm{C}$ with $29.42 \%$ residual mass which change to about $23.10 \%$ in $328-348{ }^{\circ} \mathrm{C}$. The heat evolved in decomposition of complex in temperature range $379-$ $386^{\circ} \mathrm{C}$ was found to be $9.518 \mathrm{~J} \mathrm{~mol}^{-1}$.

The DTA curve showed that two simultaneous decomposition peaks occurred during this stage at $264.99^{\circ} \mathrm{C}$ and $348.21^{\circ} \mathrm{C}$ respectively. The thermal decomposition process can be shown below:
$\mathrm{M}\left(\mathrm{L}_{1} \mathrm{H}_{2}\right) \mathrm{OH}$

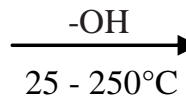
$\mathrm{M}\left(\mathrm{L}_{1} \mathrm{H}_{2}\right)$

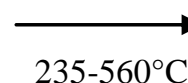
M

\section{$\mathrm{Cu}\left(\mathrm{L}_{1} \mathrm{H}_{2}\right) \mathrm{OH}$ Complex}

The TGA, DTG and DTA profiles of $\mathrm{Cu}^{2+}-\mathbf{L}_{1} \mathbf{H}_{2}$ complex are given in Fig. 7b. The single decomposition of the complex occurs in first in temperature range $190-249^{\circ} \mathrm{C}$ with mass loss of $45.21 \%$.

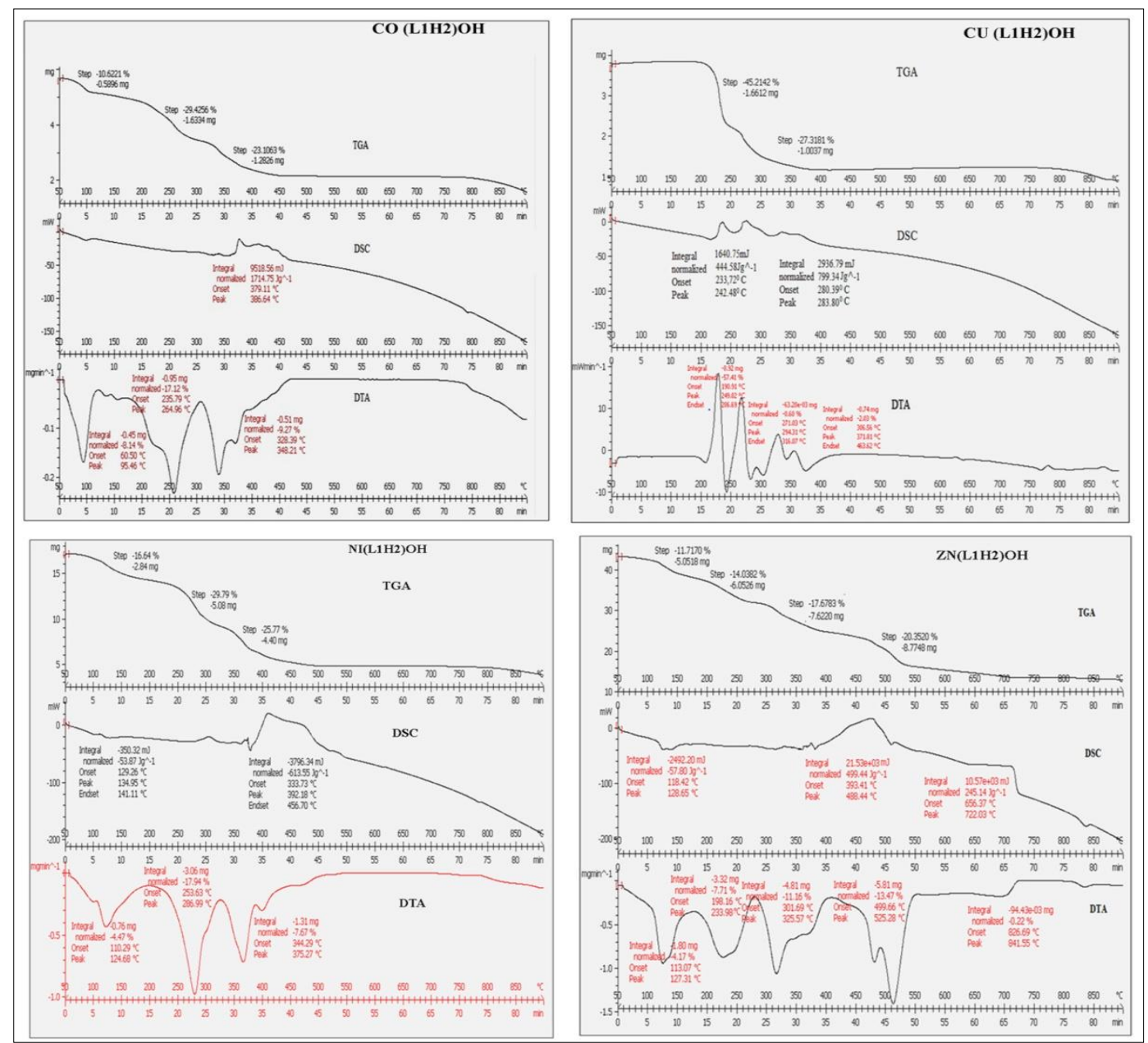

Fig. 7. The simultaneous TGA,DSC and DTA Curves of $(a) \mathrm{Co}^{2+},(\mathrm{b}) \mathrm{Ni}^{2+},(\mathrm{c}) \mathrm{Cu}^{2+}$, and (d) $\mathrm{Zn}^{2+}$ metal complexes.

The heat librated during this step was $4.445 \mathrm{~J} \mathrm{~mol}^{-1}$ which corresponds to the exothermic peak with maximum at $242.8^{\circ} \mathrm{C}$. The nature of DSC and DTA curves corresponding to this step indicates that a number of reactions are taking place simultaneously giving a stable intermediate species. The residue mass in the temperature range $371-463^{\circ} \mathrm{C}$ was found to be $27.23 \%$ and corresponding to the end product $\mathbf{L}_{1} \mathbf{H}_{2}$.

\section{$\mathrm{Ni}\left(\mathrm{L}_{1} \mathrm{H}_{2}\right) \mathrm{OH}$ Complex}

The TGA, curve (Fig. 7c) of $\mathrm{Ni}^{2+}-\mathbf{L}_{\mathbf{1}} \mathbf{H}_{2}$ complex reveals mass loss of $10.6 \%$ its water molecules in the temperature range from $60-100^{\circ} \mathrm{C}$. The total mass loss calculated from TGA curve about $72.2 \%$ up to $450^{\circ} \mathrm{C}$. DSC curve for the complex shows one broad exothermic peak in the temperature range $379-386^{\circ} \mathrm{C}$. 


\section{$\mathrm{Zn}\left(\mathrm{L}_{1} \mathrm{H}_{2}\right) \mathrm{OH}$ Complex}

The TGA, DTG and DTA profiles of $\mathrm{Zn}^{2+}-\mathbf{L}_{1} \mathbf{H}_{2}$ complex are given in Fig. 7d. The first mass loss in temperature range $50-233^{\circ} \mathrm{C}$ is of the order $25.7 \%$ which corresponds to the removal of the two water molecules. The complex decomposes in two stages in the temperature ranges $\left(301-325^{\circ} \mathrm{C}\right.$ and $\left.499-525^{\circ} \mathrm{C}\right)$ as indicated by DTA curve. The DSC profile shown residue mass of the order of $17.63 \%$ and $20 \%$ were due to formation of $\mathbf{L}_{1} \mathbf{H}_{2}$ which peaks with maxima at $488{ }^{\circ} \mathrm{C}$ and $722^{\circ} \mathrm{C}$ respectively.

\section{Conclusion}

The dicarboxylic bolaamphiphiles make complexes in water with transition-metal cations, such as $\mathrm{Co}^{2+}, \mathrm{Ni}^{2+}, \mathrm{Cu}^{2+}$, and $\mathrm{Zn}^{2+}$, producing the precipitation, colloidal dispersions and hydrogels through molecular self-assembly. FE-SEM observation revealed the metal-complexed rigid rod of $12-15 \mu \mathrm{m}$ wide. In a similar fashion as the rigid rods formed from the dicarboxylic acid homologue, the bolaamphiphiles were found to form the rigid rods by $\beta$-sheet hydrogen-bond networks between the terminal and spacer COO group residues. It is concluded that in these complexes, the mass loss as a function of temperature occurs as expected from the molecular formula as deduced from elemental analysis.

\section{Acknowledgments}

The authors are grateful to CSMCRI, (Gujarat), and AMPRI, (M.P), CSIR, INDIA, who supports this work. G.S.M acknowledges Director General, MPCST for an award of Young Scientist Training Fellowship for partial completion of the work. And we also acknowledge to SISTech, Bhopal (M.P.) for recording FT-IR spectra.

\section{References}

[1]. J.L. Wesemann, M.H. Chisholm, Inorg. Chem. (1997). 36, 3258.

[2]. M. Rusjan, Z. Chaia, O.E. Piro, D. Guillon, F.D. Cukiernik, Acta Crystallography (2000) B56, 666

[3]. H. Miyasaka, C.S. Campos-Fernandez, R. Clerac, K.R. Dunbar, Angew. Chem. Int. Ed. (2000) 393831

[4]. P.N. Baxter, Metal Ion Directed Assembly of Complex Molecular Architectures and Nanostructures, Elsevier Science, Oxford, UK. (1996).

[5]. Wei-Fang Su, Yin-Chung Lee, Wei-Ping Pan, Thermochimica Acta (2002), 392-393, 395-398

[6]. J. M. Lehn, A. Rigault, Angew. Chem. Int. Ed. Engl. (1988) 27, 1095

[7]. J.H. Fuhrhop, H.-H. David, J. Mathieu, U. Liman, H.-J. Winter and E. Boekema, J. Am. Chem. Soc., (1986), $108,1785$.

[8]. J.-H. Fuhrhop, C. Demoulin, J. Rosenberg and C. Boettcher, J. Am. Chem. Soc., (1990), 112, 2827.

[9]. B. S. Sekhon, L. Gandhi, International Journal of ChemTech Research, (2010)1057-1060.

[10]. J. H. Esch, A. L. H. V. Stols, R. J. M. Nolte, J. Chem. Soc. Chem. Commun. (1990), 1658.

[11]. (a) E. Tsuchida, T. Komatsu, K. Arai, K. Yamada, H. Nishide, J.H. Fuhrhop, 1995, Langmuir 11, 1877. (b) N.A.J.M. Sommerdijk, K.J. Booy, A.M.A. Pistorius, M.C. Feiters, R.J.M. Nolte, B. Zwanenburg, 1999, Langmuir 15, 7008.

[12]. D. Khatau, R. Maiti, J. Dey, Chem. Commun. (2006), 4903.

[13]. J.P. Douliez, C. Gaillard, L. Navailles, F. Nallet, Langmuir (2006) 22, 2942.

[14]. Alma Valor, Edilso Reguera, Enelio Torres-Garcia, Silvia Mendoza, Feliciano Sanchez-Sinencio, Thermochemica Acta 389 (2002) 133-139

[15]. V. Logvinenko, L. Yudanova, N. Yudanov and G. Chekhova. Journal of Thermal Analysis and Calorimetry, Vol. 74 (2003) 395399.

[16]. P. Mosae Selvakumar, E. Suresh, P.S. Subramanian, Journal of Molecular Structure (2009) 919, 72-78.

[17]. P. Mosae Selvakumar, E. Suresh, P.S. Subramanian, Inorganica Chimica Acta , (2008) 361, 1503-1509.

[18]. P. Mosae Selvakumar, Giriraj Mandloi, Eringathodi Suresh, Palani Sivagnana Subramanian, Organic Chemistry: An Indian Journal, (2010).

[19]. J. H. Fuhrhop, Tianyu Wang, , Chem. Rev. (2004) 104, 2901-2937.

[20]. T. Shimizu, Journal of Polymer Science: Part A: Polymer Chemistry, (2008), 46, 2601-2611.

[21]. M. Masuda, T. Shimizu, Chem. Commun. (1996), 1057

[22]. A. Aggeli, M. Bell, N. Boden, et al., Nature (1997) 386, 259. 